\title{
Comparison and commutability study between standardized liquid chromatography-mass spectrometry/mass spectrometry (LC-MS/MS) and chemiluminescent enzyme immunoassay for aldosterone measurement in blood
}

Tetsuo Nishikawa ${ }^{1)}$, Fumitoshi Satoh ${ }^{2)}$, Yuichi Takashi ${ }^{3)}$, Toshihiko Yanase ${ }^{4)}$, Hiroshi (toh $^{5)}$, Isao Kurihara ${ }^{5), 6)}$, Hirotaka Shibata $^{7)}$, Yutaka $\mathrm{Oki}^{8}$, Mitsuhide Naruse ${ }^{9)}$, Hidehiko Sasamoto ${ }^{10)}$ and Katsuhiko Kuwa ${ }^{11)}$

\footnotetext{
1) Endocrinology and Diabetes Center, Yokohama Rosai Hospital, Yokohama, Japan

2) Division of Clinical Hypertension, Endocrinology and Metabolism, Tohoku University Graduate School of Medicine, Division of Nehrology, Endocrinology and Vascular Medicine, Tohoku University Hospital, Sendai, Japan

3) Department of Endocrinology and Diabetes Mellitus, Fukuoka University School of Medicine, Fukuoka, Japan

4) Muta Hospital, Fukuoka, Japan

5) Department of Endocrinology, Metabolism and Nephrology, Keio University School of Medicine, Tokyo, Japan

6) Department of Medical Education, National Defense Medical College, Tokorozawa, Japan

7) Department of Endocrinology, Metabolism, Rheumatology and Nephrology, Faculty of Medicine, Oita University, Yufu, Japan

8) Department of Metabolism and Endocrinology, Hamamatsu-Kita Hospital, Hamamatsu, Japan

9) Department of Endocrinology, Metabolism and Hypertension, National Hospital, Organization Kyoto Medical Center, Kyoto, Japan

10) Aska Pharma Medical Co. Ltd., Fujisawa, Japan

11) Japan Reference Measurement Institute, Tsukuba, Japan
}

\begin{abstract}
A commutability confirmation test for the blood aldosterone measurement was performed on liquid chromatography-mass spectrometry/mass spectrometry (LC-MS/MS) as a designated comparison method (DCM) and four chemiluminescent enzyme immunoassay (CLEIA) measurement procedures based on metrological traceability. A conventional radioimmunoassay (RIA) and two measurement procedures of CLEIA which obtains RIA equivalent values were also compared. The relationship between the DCM value and the CLEIA value with respect to $120 \mathrm{pg} / \mathrm{mL}$ of the RIA value, which is the screening criterion of primary aldosteronism (PA) was clarified. For the correlation test, 75 samples of patient serum and plasma were used. Regression analysis revealed that the standardized LC-MS/MS and four CLEIA measurement procedures were in good agreement. This is the effect of measurement specificity and calibration using by certified reference material (CRM). The median of the LC-MS/MS corresponding to $120 \mathrm{pg} / \mathrm{mL}$ of RIA was $48.5 \mathrm{pg} / \mathrm{mL}$. In the mean of standardized four CLEIA values corresponding to the $48.5 \mathrm{pg} / \mathrm{mL}$ of LC-MS/MS value was $47.51 \mathrm{pg} / \mathrm{mL}$ and the standard deviation (SD) was $2.93 \mathrm{pg} / \mathrm{mL}$. However, the correlation between the RIA value and the RIA equivalent of the two measurement procedures by CLEIA differed depending on the measurement procedure. This is due to the influence of RIA measurement performance. Standardized CLEIA measurements are suitable for routine measurement procedure. When converting the LC-MS/MS equivalent value by the standardized CLEIA to the conventional RIA value, it is necessary to use the conversion formula.
\end{abstract}

Key words: Standardization, Traceability, Liquid chromatography-mass spectrometry/mass spectrometry, Commutability, Primary aldosteronism

IN THIS STANDARDIZATION of blood aldosterone measurement, the establishment of serum based certified

Submitted May 8, 2021; Accepted Jun. 26, 2021 as EJ21-0278 Released online in J-STAGE as advance publication Jul. 22, 2021 Correspondence to: Tetsuo Nishikawa, Endocrinology and Diabetes Center, Yokohama Rosai Hospital, 3211 Kozukue-cho, Kohoku-ku, Yokohama City, Kanagawa 222-0036, Japan.

E-mail: tetsuon@yokohamah.johas.go.jp reference material (CRM) to promote the development of new kits by chemiluminescent enzyme immunoassay (CLEIA) and others was mainly concerning because the supply of Spac-S ${ }^{\circledR}$ aldosterone kit using radioimmunoassay (RIA) was scheduled to be stopped suppling [1]. Therefore, "Aldosterone in Huma Serum (NMIJ CRM 6402)" with an isotope dilution-liquid chromatographymass spectrometry/mass spectrometry (ID-LC-MS/MS) 
certified value has been established at the National Metrology Institute of Japan (NMIJ), National Institute of Advanced Industrial Science and Technology (AIST) ahead of the rest of the world [2].

As a result, this CRM can be used as a reference for calibration of non-RIA measurement procedures, which results in SI traceable measurements of the clinical specimen. Particularly, this CRM has been calibrated for liquid chromatography-mass spectrometry/mass spectrometry (LC-MS/MS) as a designated comparison method (DCM), which is a specified and authorized comparative method for blood aldosterone measurement and calibrated for new CLEIA measurement procedures and approved for new kits for in vitro diagnosis.

Subsequently, the Aldosterone Measurement Standardization Investigation Committee of the Japan Endocrine Society presented operational guidelines for the standardization of aldosterone measurement for clinical-Spac-S ${ }^{\circledR}$ Aldosterone kit by conventional RIA (response to discontinuation of the RIA kit, method of application of NMIJ CRM 6402, and application procedure of the conversion formula for $\mathrm{Spac} \mathrm{S}^{\circledR}$ ) [3, 4]. Furthermore, LC-MS/MS determination is now developing for clinical laboratory examination for much more definite estimation of aldosterone with high reproducibility [5-7].

Finally, following the report that the supply of SPAC$\mathrm{S}^{\circledR}$ Aldosterone kit will be discontinued in March 2021, the Committee between will conduct a confirmation test on the maintenance of the commutability the current kits and prepare a document on future responses [8].

In this study, blood aldosterone measurement comparison and commutability confirmation test performed using clinical specimens are used to clarify the commutability of the RIA equivalent values, commutability of the LC-MS/MS value and LC-MS/MS equivalent value, and commutability of the RIA equivalent value for a total of seven kits consisting of one RIA kit and six CLEIA kits. Furthermore, the relationship between the DCM value and the CLEIA value with respect to $120 \mathrm{pg} / \mathrm{mL}$ of the RIA value, which is the screening criterion of primary aldosteronism (PA) was clarified.

\section{Materials and Methods}

\section{Working flowchart for comparison and commutability study of aldosterone measurement}

Working flowchart for comparison and commutability study of aldosterone measurement is shown in Fig. 1. In this study, a total of seven kits were used, including LCMS/MS and former RIA. That is, the kit for the routine measurement procedure of blood aldosterone concentration is provided for clinical tests by two measurement procedures, one kit of RIA as a conventional measurement procedure and two kits of CLEIA with an equivalent value to this RIA value. And as a metrological traceability system, calibrated using NMIJ CRM 6402 whose certified value was determined by SI traceable IDLC-MS/MS, and two kits by CLEIA equivalent to LCMS/MS calibrated by NMIJ CRM 6402 for patient specimens. In addition, four kits by CLEIA, which are equivalent to the LC-MS/MS calibrated by NMIJ CTM 6402, are now available.

\section{Participated procedures}

Participated procedures of the comparison and commutability confirmation test are shown in Table 1 . The participating measurement procedures were a DCM and seven kits for one kit by RIA and six kits by CLEIA.

\section{Clinical specimens}

As clinical specimens, a total of 75 stocked specimens approved by the Institutional Review Board of the institution were used for serum or plasma samples from the three clinical committee hospitals, including Yokohama Rosai Hospital, Tohoku University Hospital and Fukuoka University Hospital. Fifty serum and 205 plasma samples from patients with primary aldosteronism in Yokohama Rosai Hospital and Tohoku University Hospital were partly mixed for making enough amounts of 23 and 41 pooled samples, respectively. Sixteen serum samples from 13 cases with primary aldosteronism and 3 diabetic patients in Fukuoka University Hospital were partly mixed for making enough amounts of 12 pooled samples. Of the 76 test samples, one was below the lower measurement limit. Then we omitted this sample for further analysis. AVS samples also included among them.

We partly used the same samples which were pooled and stored for the present examination as used previously for the study on the calibration and evaluation of routine methods by serum certified reference material [4]. Newly collected samples, which were prepared at Fukuoka University Hospital, were also used. Sample collection was implemented after obtaining informed consent from the patient and with the approval of the ethical review boards in the applicable facility. The concentration range of patient specimens by LC-MS/MS are shown in Table 2.

\section{Measurements}

In LC-MS/MS measurement, 75 clinical specimens were divided into two groups, and each group was measured for two days. The quality control material was measured simultaneously. Measurements using seven kits (RIA-S, CLEIA-D1, CLEIA-D2, CLEIA-A1, CLEIA-A2, CLEIA-L1 and CLEIA-L2) were performed 


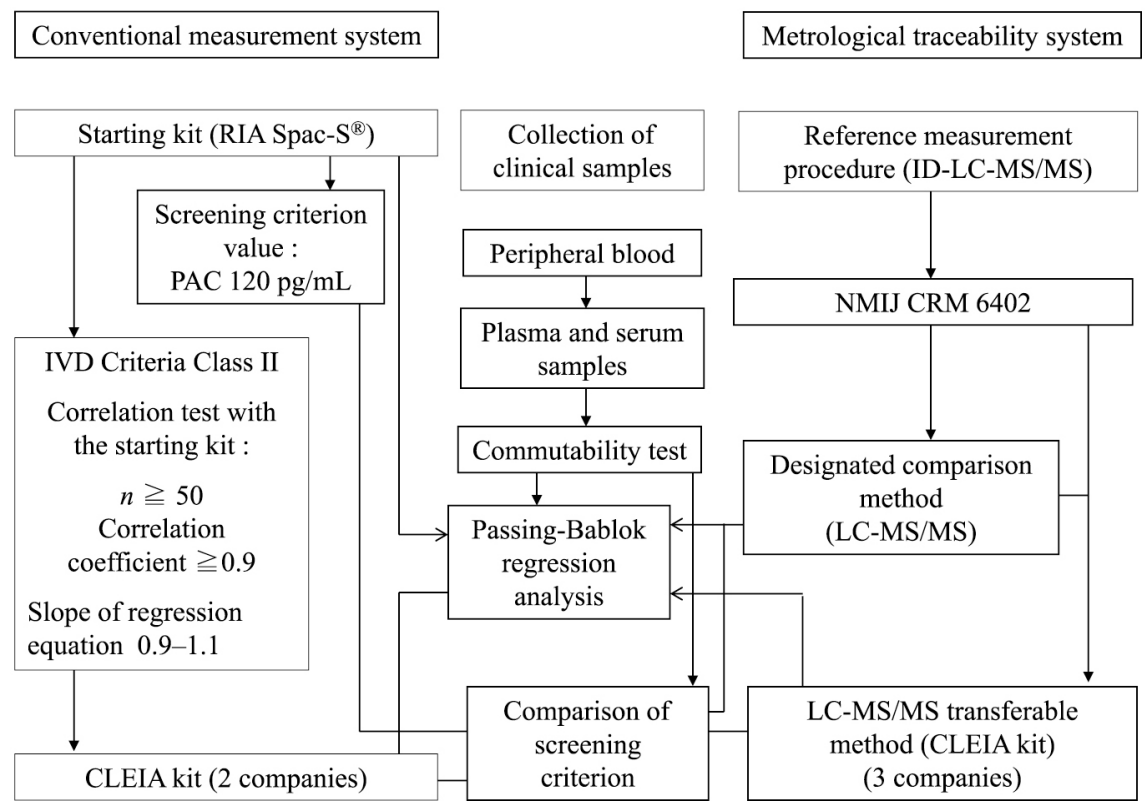

Fig. 1 Working flowchart for comparison and commutability study of aldosterone measurement.

CRM, certified reference material; NMIJ, National Metrology Institute of Japan

Table 1 Participated Procedures

\begin{tabular}{|c|c|c|c|c|c|c|}
\hline $\begin{array}{l}\text { Measurement } \\
\text { procedure }\end{array}$ & Methodology & $\begin{array}{c}\text { Automated } \\
\text { Chemiluminescence } \\
\text { System }\end{array}$ & $\begin{array}{l}\text { Metrological } \\
\text { traceability }\end{array}$ & $\begin{array}{l}\text { Measurement } \\
\text { range }(\mathrm{pg} / \mathrm{mL})\end{array}$ & Unit of expression & Implementation \\
\hline $\begin{array}{l}\text { Designated } \\
\text { comparison method } \\
\text { (LC-MS/MS) }\end{array}$ & LC-MS/MS & - & $\begin{array}{c}\text { ID-LC-MS/MS } \\
\text { (NMIJ CRM 6402) }\end{array}$ & $5 \sim 5,000$ & MS (pg/mL) & $\begin{array}{c}\text { Aska Pharma Medical } \\
\text { Co., Ltd., Japan }\end{array}$ \\
\hline RIA-S* & RIA & - & - & $25 \sim 1,600$ & RIA (pg/mL) & Fujirebio Inc., Japan \\
\hline CLEIA-D1 (RIA) & CLEIA & CL-JACK ${ }^{\circledR} \mathrm{NX}$ & - & $17.0 \sim 1,600.0$ & $\begin{array}{l}\text { RIA equivalent } \\
\quad(\mathrm{pg} / \mathrm{mL})\end{array}$ & $\begin{array}{l}\text { Hitachi Chemical } \\
\text { Diagnostic Systems } \\
\text { Co., Ltd., Japan }\end{array}$ \\
\hline CLEIA-D2 (MS)** & CLEIA & $\begin{array}{l}\text { Candidate CL- } \\
\text { JACK }{ }^{\circledR} \mathrm{NX}\end{array}$ & $\begin{array}{c}\text { ID-LC-MS/MS } \\
\text { (NMIJ CRM 6402) }\end{array}$ & $13.0 \sim 1,200.0$ & $\begin{array}{l}\text { MS equivalent } \\
(\mathrm{pg} / \mathrm{mL})\end{array}$ & \\
\hline CLEIA-A1 (RIA) & CLEIA & Accuraseed $^{\circledR}$ & - & $50 \sim 1,600$ & $\begin{array}{l}\text { RIA equivalent } \\
\qquad(\mathrm{pg} / \mathrm{mL})\end{array}$ & $\begin{array}{l}\text { Fujifilm Wako Pure } \\
\text { Chemical } \\
\text { Corporation, Japan }\end{array}$ \\
\hline CLEIA- A2 (MS)** & CLEIA & Candidate Accuraseed $^{\circledR}$ & $\begin{array}{c}\text { ID-LC-MS/MS } \\
\text { (NMIJ CRM 6402) }\end{array}$ & $4 \sim 3,200$ & $\begin{array}{l}\text { MS equivalent } \\
\quad(\mathrm{pg} / \mathrm{mL})\end{array}$ & \\
\hline CLEIA- L1 (MS) & CLEIA & Lumipulse Presto ${ }^{\circledR}$ & $\begin{array}{c}\text { ID-LC-MS/MS } \\
\text { (NMIJ CRM 6402) }\end{array}$ & $4.0 \sim 2,000$ & $\begin{array}{l}\text { MS equivalent } \\
\quad(\mathrm{pg} / \mathrm{mL})\end{array}$ & Fujirebio Inc., Japan \\
\hline CLEIA- L2 (MS) & CLEIA & Lumipulse $G^{\circledR}$ & $\begin{array}{c}\text { ID-LC-MS/MS } \\
\text { (NMIJ CRM 6402) }\end{array}$ & $7.9 \sim 2,000$ & $\begin{array}{l}\text { MS equivalent } \\
\quad(\mathrm{pg} / \mathrm{mL})\end{array}$ & \\
\hline
\end{tabular}

ID-LC/MS/MS, isotope dilution-liquid chromatography/mass spectrometry/mass spectrometry; NMIJ, National Metrology Instituteof Japan; CRM, certified reference material; LC-MS/MS, liquid chromatography-mass spectrometry/mass spectrometry; RIA, radioimmunoassay; CLEIA, chemiluminescent enzyme immunoassay

* Spac-S $\mathrm{S}^{\circledR}$ Aldosterone kit, ** candidate routine method

according to the standard operating procedure of each kit. For the measured values of the four standardized kits (CLEIA-D2, CLEIA-A2, CLEIA-L1 and CLEIA-L2), the RIA equivalent values (the value that approximates $y$ $=\mathrm{x}(\mathrm{RIA}-\mathrm{S})$ in the regression equation) was calculated using the conversion formula specified in each kit.

Aldosterone values estimated by RIA-S, CLEIA-A1, and CLEIA-D1 were used as "RIA value". Each value determined by CLEIA-A2, CLEIA-D2, CLEIA-L1, and CLEIA-L2 were used as LC-MS/MS equivalent value. 
Table 2 Aldosterone concentrations of specimens for comparison and commutability confirmation test

\begin{tabular}{rcc}
\hline$N$ & \% of specimens & $\begin{array}{c}\text { Aldosterone concentration }(\mathrm{pg} / \mathrm{mL}) \\
\text { (LC-MS/MS) }\end{array}$ \\
\hline 7 & 9.3 & $5.1 \sim 26.2$ \\
23 & 28.0 & $31.9 \sim 98.8$ \\
13 & 17.3 & $106.0 \sim 194.7$ \\
\hline 12 & 16.0 & $201.0 \sim 395.2$ \\
14 & 18.7 & $401.7 \sim 765.9$ \\
\hline 6 & 8.0 & $832.9 \sim 1,012.0$ \\
\hline 2 & 2.7 & $1,272.6 \sim 1,328.9$ \\
\hline
\end{tabular}

For the reported values used in the analysis, the measured values obtained with the kit were used as the RIA values for RIA-S, CLEIA-A1 and CLEIA-D1, and for CLEIA-A2, CLEIA-D2, CLEIA-L1 and CLEIA-L2, the measured values obtained by the kit were used as LCMS/MS equivalent values. Furthermore, for CLEIA-A2, CLEIA-D2, CLEIA-L1, and CLEIA-L2, it was the reported value of the RIA conversion value. It is an RIA conversion value obtained by using a conversion formula by the manufacturer of the kit for the measured value obtained by the kit. These were used as RIA equivalent values. The conversion formula applied in the reported values in this study was not published at the time of the study.

\section{Data analysis}

MedCalc Software bvba (MedCalc Software, Belgium) was used to analyze the measurement values. Statistical analysis was performed for conducting Passing-Bablok regression.

\section{Results}

\section{Measurement results of LC-MS/MS}

The intermediate precision of the quality control material including the measurement periods was $N=5$; the average value was $501.3 \mathrm{pg} / \mathrm{mL}$, the standard deviation (SD) was $20.2 \mathrm{pg} / \mathrm{mL}$, and the coefficient of variation (CV) was $4.0 \%$.

\section{Regression analysis with LC-MS/MS}

The results of the Passing-Bablok regression analysis with LC-MS/MS are shown in Fig. 2. The regression analysis results shown include the number of samples $(n)$, the correlation coefficient $(r)$ and the 95\% confidence interval $(95 \% \mathrm{CI})$, the intercept of the regression equation and the $95 \%$ confidence interval $(95 \% \mathrm{CI})$, the slope of the regression equation and the $95 \%$ confidence interval $(95 \% \mathrm{CI})$, respectively.

As a result, the regression analysis of the RIA values for LC-MS/MS in all measurements showed correlation coefficients of $0.988-0.995$, intercepts from -10.5 to $61.0 \mathrm{pg} / \mathrm{mL}$, and slopes of $1.217-1.364$.

\section{Regression analysis with RIA}

The results of the Passing-Bablok regression analysis with RIA-S (Spac-S ${ }^{\circledR}$ ) are shown in Fig. 3. The regression analysis results shown include the number of samples $(n)$, the correlation coefficient $(r)$ and the $95 \%$ confidence interval $(95 \% \mathrm{CI})$, the intercept of the regression equation and the $95 \%$ confidence interval $(95 \% \mathrm{CI})$, the slope of the regression equation and the $95 \%$ confidence interval (95\% CI), respectively.

The regression analysis of the RIA values for RIA $\left(\right.$ Spac- $\mathrm{S}^{\circledR}$ ) in all measurements showed correlation coefficients of $0.984-0.989$, intercepts of $-83.9 \mathrm{pg} / \mathrm{mL}$ to $-34.5 \mathrm{pg} / \mathrm{mL}$, and slope values of $1.120-1.134$.

\section{Comparison of values corresponding to the screening criterion of PAC $120 \mathrm{pg} / \mathrm{mL}$ by using RIA}

The results of the comparison of LC-MS/MS value, LC-MS/MS equivalent values and RIA equivalent values of the screening criterion of PAC $120 \mathrm{pg} / \mathrm{mL}$ by RIA are shown in Table 3.

In comparison of LC-MS/MS value and LC-MS/MS equivalent values of CLEIA-D2, CLEIA-A2, CLEIAL1 and CLEIA-L2, the median value of the LC-MS/MS value was $48.5 \mathrm{pg} / \mathrm{mL}$, and LC-MS/MS equivalent values for each measurement procedure corresponding to $48.5 \mathrm{pg} / \mathrm{mL}$ of LC-MS/MS value was $43.5 \mathrm{pg} / \mathrm{mL}, 49.3$ $\mathrm{pg} / \mathrm{mL}, 50.0 \mathrm{pg} / \mathrm{mL}$ and $47.4 \mathrm{pg} / \mathrm{mL}$, respectively. The mean value and standard deviation (mean $\pm \mathrm{SD}$ ) was $47.51 \pm 2.93 \mathrm{pg} / \mathrm{mL}$. The lower and upper limits of the $95 \%$ confidence interval in the kit ranged from 35.8 to $53.9 \mathrm{pg} / \mathrm{mL}$.

In comparison of RIA equivalent values of CLEIA-D1 and CLEIA-A1, the median value of the RIA equivalent values were $52.2 \mathrm{pg} / \mathrm{mL}$ and $99.9 \mathrm{pg} / \mathrm{mL}$, respectively.

In comparison of RIA equivalent values of CLEIAD2, CLEIA-A2, CLEIA-L1 and CLEIA-L2, the median value of the LC-MS/MS equivalent values (the value that approximates $\mathrm{y}=\mathrm{x}$ (RIA-S) in the regression equation) for each measurement procedures were $106.9 \mathrm{pg} / \mathrm{mL}$, $106.9 \mathrm{pg} / \mathrm{mL}, 99.9 \mathrm{pg} / \mathrm{mL}$ and $93.9 \mathrm{pg} / \mathrm{mL}$, respectively. The mean value and standard deviation (mean $\pm \mathrm{SD}$ ) was $101.68 \pm 5.42 \mathrm{pg} / \mathrm{mL}$. The lower and upper limits of the $95 \%$ confidence interval in the kit ranged from 81.7 to $122.9 \mathrm{pg} / \mathrm{mL}$.

\section{Discussion}

Currently, there are a total of five kits for measuring blood aldosterone used in clinical laboratory tests from 

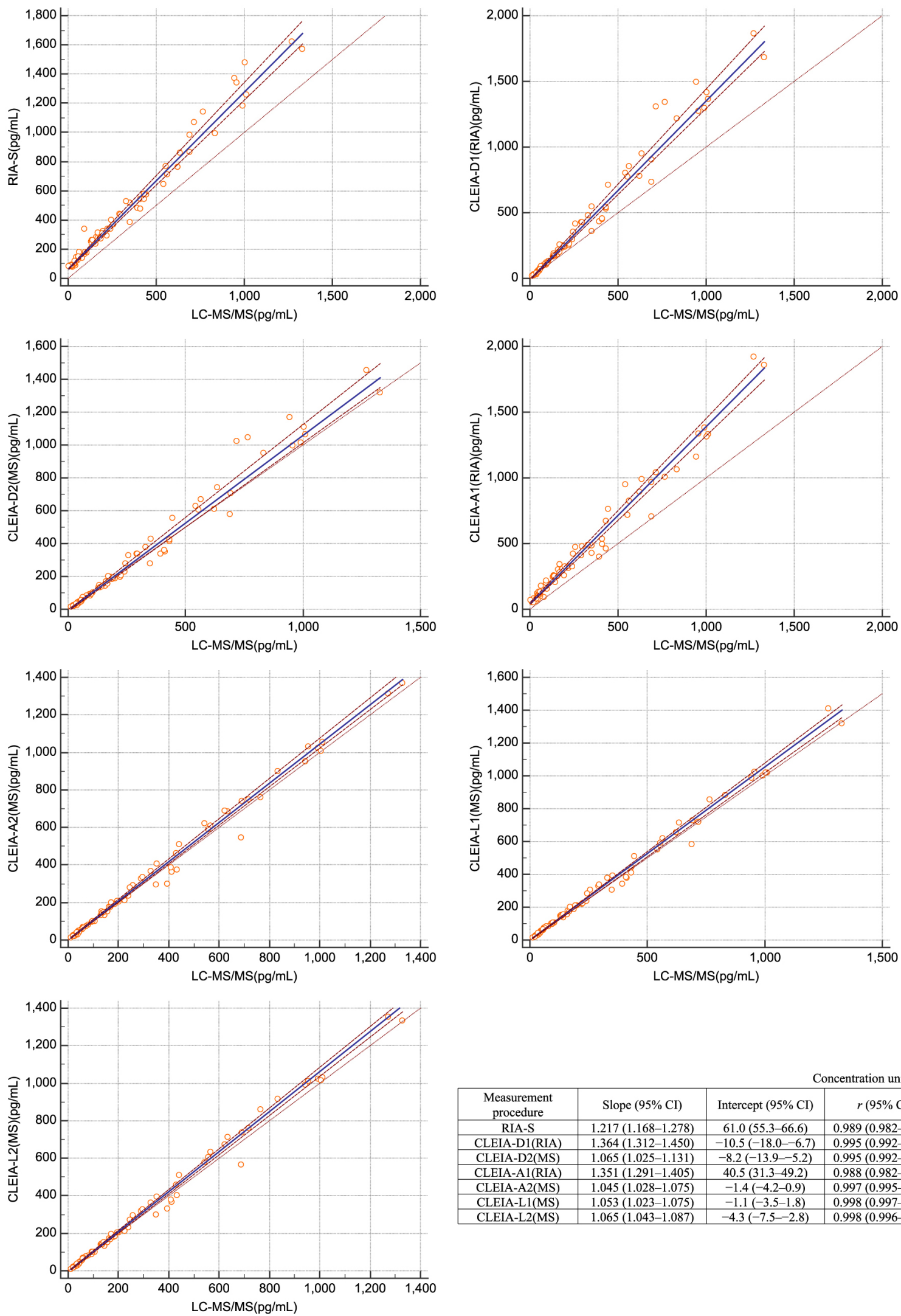

\begin{tabular}{|c|c|c|c|c|}
\hline \multicolumn{4}{|c|}{ Concentration unit : $\mathrm{pg} / \mathrm{mL}$} \\
\hline $\begin{array}{c}\text { Measurement } \\
\text { procedure }\end{array}$ & Slope $(95 \% \mathrm{CI})$ & Intercept $(95 \% \mathrm{CI})$ & $r(95 \% \mathrm{CI})$ & $n$ \\
\hline RIA-S & $1.217(1.168-1.278)$ & $61.0(55.3-66.6)$ & $0.989(0.982-0.993)$ & 75 \\
\hline CLEIA-D1(RIA) & $1.364(1.312-1.450)$ & $-10.5(-18.0-6.7)$ & $0.995(0.992-0.997)$ & 74 \\
\hline CLEIA-D2(MS) & $1.065(1.025-1.131)$ & $-8.2(-13.9--5.2)$ & $0.995(0.992-0.997)$ & 74 \\
\hline CLEIA-A1(RIA) & $1.351(1.291-1.405)$ & $40.5(31.3-49.2)$ & $0.988(0.982-0.993)$ & 75 \\
\hline CLEIA-A2(MS) & $1.045(1.028-1.075)$ & $-1.4(-4.2-0.9)$ & $0.997(0.995-0.998)$ & 74 \\
\hline CLEIA-L1(MS) & $1.053(1.023-1.075)$ & $-1.1(-3.5-1.8)$ & $0.998(0.997-0.999)$ & 74 \\
\hline CLEIA-L2(MS) & $1.065(1.043-1.087)$ & $-4.3(-7.5--2.8)$ & $0.998(0.996-0.999)$ & 74 \\
\hline
\end{tabular}

Fig. 2 Passing-Bablok regression analysis and Peason correlation coefficient for aldosterone in bloods between designated comparison method (LC-MS/MS) and routine measurement procedure. Aldosterone concentration as measured by each of the routine measurement procedures (RIA-S, CLEIA-D1, D2, A1, A2, L1, L2) are plotted against aldosterone concentrations by the designated comparison method (LC-MS/MS). Solid line, regression line. Dashed line, 95\% CI. Dotted line, line of equality. 

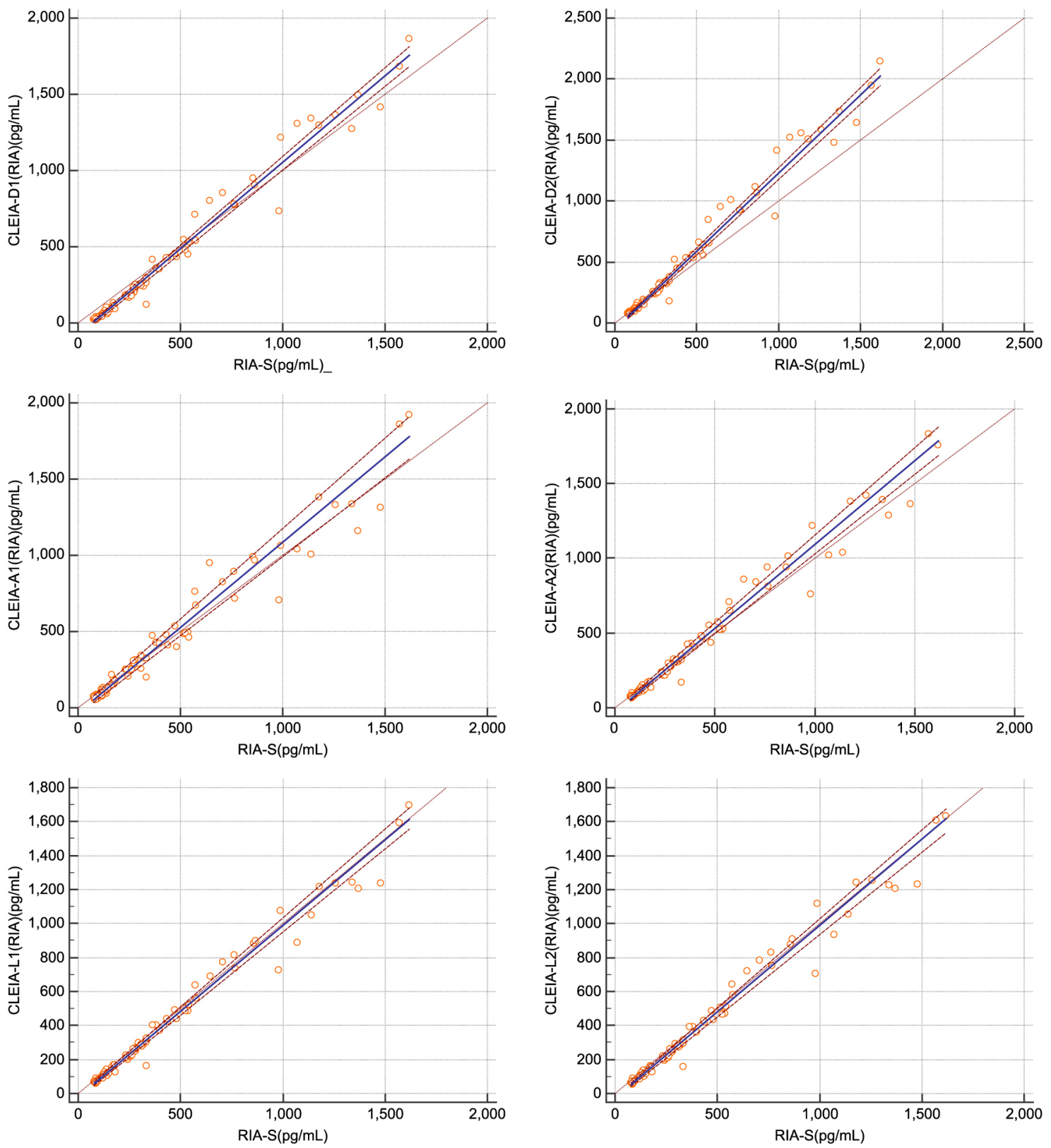

\begin{tabular}{|c|c|c|c|c|}
\hline $\begin{array}{c}\text { Measurement } \\
\text { procedure }\end{array}$ & Slope $(95 \% \mathrm{CI})$ & Intercept $(95 \% \mathrm{CI})$ & $r(95 \% \mathrm{CI})$ & $n$ \\
\hline CLEIA-D1(RIA) & $1.134(1.097-1.166)$ & $-83.9(-93.9-75.4)$ & $0.989(0.983-0.993)$ & 74 \\
\hline CLEIA-D2(RIA) & $1.278(1.237-1.312)$ & $-46.5(-57.6-37.2)$ & $0.989(0.983-0.993)$ & 74 \\
\hline CLEIA-A1(RIA) & $1.120(1.036-1.186)$ & $-34.5(-47.2--15.0)$ & $0.984(0.975-0.990)$ & 75 \\
\hline CLEIA-A2(RIA) & $1.118(1.065-1.169)$ & $-27.3(-38.0--17.4)$ & $0.988(0.982-0.993)$ & 74 \\
\hline CLEIA-L1(RIA) $^{*}$ & $1.009(0.977-1.045)$ & $-22.1(-30.4-14.4)$ & $0.990(0.984-0.994)$ & 74 \\
\hline CLEIA-L2(RIA) ${ }^{*}$ & $1.016(0.967-1.045)$ & $-28.0(-34.3--17.7)$ & $0.990(0.984-0.994)$ & 74 \\
\hline
\end{tabular}
*alue converted from MS equivalent value to RIA equivalent value

Fig. 3 Passing-Bablok regression analysis and Peason correlation coefficient for aldosterone in bloods between RIA-S and CLEIA (D1, A1) of RIA equivalent values, and CLEIA (D2, A2, L1, L2) of RIA conversion value reported by Manufacturer.

Aldosterone concentration as measured by each of the routine measurement procedures (CLEIA-D1, D2, A1, A2, L1, L2) are plotted against aldosterone concentrations by the RIA-S. Solid line, regression line. Dashed line, $95 \%$ CI. Dotted line, line of equality

three companies. Of these, the non-standardized kits are one RIA kit and two CLEIA kits, and the standardized kits are four CLEIA kits.

Therefore, we have set up a measurement system with the aim of shifting from RIA to nonRIA [3, 4]. As a result, SI traceable CRM has been established and standardized LC-MS/MS as a DCM and CLEIA kits have been generalized (Fig. 1). 
Table 3 Comparison of value corresponding to the screening criterion value of PAC

1) Comparison of RIA-S, CLEIA-D1, CLEIA-D2, CLEIA-A1, CLEIA-A2, CLEIA-L1 and CLEIA-L2

\begin{tabular}{lcr}
\hline RIA-S & $\mathrm{pg} / \mathrm{mL}$ & 120 \\
\hline CLEIA-D1 (CRM-uncalibrated) & Lower limit $(\mathrm{pg} / \mathrm{mL})$ & 37.7 \\
RIA equivalent & Median $(\mathrm{pg} / \mathrm{mL})$ & 52.2 \\
& Upper limit $(\mathrm{pg} / \mathrm{mL})$ & 64.5 \\
\hline \multirow{2}{*}{ CLEIA-D2 (CRM-calibrated) } & Lower limit $(\mathrm{pg} / \mathrm{mL})$ & 90.8 \\
RIA equivalent & Median $(\mathrm{pg} / \mathrm{mL})$ & 106.9 \\
& Upper limit $(\mathrm{pg} / \mathrm{mL})$ & 120.2 \\
CLEIA-A1 (CRM-uncalibrated) & Lower limit $(\mathrm{pg} / \mathrm{mL})$ & 77.1 \\
RIA equivalent & Median $(\mathrm{pg} / \mathrm{mL})$ & 99.9 \\
& Upper limit $(\mathrm{pg} / \mathrm{mL})$ & 127.3 \\
\hline \multirow{2}{*}{ CLEIA-A2 (CRM-calibrated) } & Lower limit $(\mathrm{pg} / \mathrm{mL})$ & 89.8 \\
RIA equivalent & Median $(\mathrm{pg} / \mathrm{mL})$ & 106.9 \\
& Upper limit $(\mathrm{pg} / \mathrm{mL})$ & 122.9 \\
CLEIA-L1 (CRM-calibrated) & Lower limit $(\mathrm{pg} / \mathrm{mL})$ & 86.8 \\
RIA equivalent & Median $(\mathrm{pg} / \mathrm{mL})$ & 99.0 \\
& Upper limit $(\mathrm{pg} / \mathrm{mL})$ & 111.0 \\
\hline CLEIA-L2 (CRM-calibrated) & Lower limit $(\mathrm{pg} / \mathrm{mL})$ & 81.7 \\
RIA equivalent & Median $(\mathrm{pg} / \mathrm{mL})$ & 93.9 \\
& Upper limit $(\mathrm{pg} / \mathrm{mL})$ & 107.7 \\
\hline
\end{tabular}

2) Comparison of RIA-S and LC-MS/MS

\begin{tabular}{lcc}
\hline RIA-S & $\mathrm{pg} / \mathrm{mL}$ & 120 \\
\hline \multirow{2}{*}{ LC-MS/MS (CRM-calibrated) } & Lower limit $(\mathrm{pg} / \mathrm{mL})$ & 41.8 \\
& Median $(\mathrm{pg} / \mathrm{mL})$ & 48.5 \\
& Upper limit $(\mathrm{pg} / \mathrm{mL})$ & 55.4 \\
\hline
\end{tabular}

3) Comparison of LC-MS/MS, CLEIA-D1 and CLEIA-A1

\begin{tabular}{lcc}
\hline LC-MS/MS (CRM-calibrated) & $\mathrm{pg} / \mathrm{mL}$ & 48.5 \\
\hline \multirow{2}{*}{ CLEIA-D1 (CRM-uncalibrated) } & Lower limit $(\mathrm{pg} / \mathrm{mL})$ & 45.6 \\
RIA equivalent & Median $(\mathrm{pg} / \mathrm{mL})$ & 55.7 \\
& Upper limit $(\mathrm{pg} / \mathrm{mL})$ & 63.6 \\
& Lower limit $(\mathrm{pg} / \mathrm{mL})$ & 93.9 \\
CLEIA-A1 (CRM-uncalibrated) & Median $(\mathrm{pg} / \mathrm{mL})$ & 106.0 \\
RIA equivalent & Upper limit $(\mathrm{pg} / \mathrm{mL})$ & 117.3 \\
\hline
\end{tabular}

4) Comparison of LC-MS/MS, CLEIA-D2, CLEIA-A2, CLEIA-L1 and CLEIA-L2

\begin{tabular}{|c|c|c|c|c|c|}
\hline LC-MS/MS (CRM-calibrated) & $\mathrm{pg} / \mathrm{mL}$ & 48.5 & LC-MS/MS (CRM-calibrated) & $\mathrm{pg} / \mathrm{mL}$ & 48.5 \\
\hline \multirow{3}{*}{$\begin{array}{l}\text { CLEIA-D2 (CRM-calibrated) } \\
\text { MS equivalent }\end{array}$} & Lower limit $(\mathrm{pg} / \mathrm{mL})$ & 35.8 & \multirow{3}{*}{$\begin{array}{l}\text { CLEIA-D2 (CRM-calibrated) } \\
\text { RIA equivalent* }\end{array}$} & Lower limit $(\mathrm{pg} / \mathrm{mL})$ & 98.9 \\
\hline & Median (pg/mL) & 43.5 & & Median $(\mathrm{pg} / \mathrm{mL})$ & 110.7 \\
\hline & Upper limit (pg/mL) & 49.7 & & Upper limit (pg/mL) & 119.8 \\
\hline \multirow{3}{*}{$\begin{array}{l}\text { CLEIA-A2 (CRM-calibrated) } \\
\text { MS equivalent }\end{array}$} & Lower limit (pg/mL) & 45.7 & \multirow{3}{*}{$\begin{array}{l}\text { CLEIA-A2 (CRM-calibrated) } \\
\text { RIA equivalent* }\end{array}$} & Lower limit $(\mathrm{pg} / \mathrm{mL})$ & 103.6 \\
\hline & Median (pg/mL) & 49.3 & & Median (pg/mL) & 108.4 \\
\hline & Upper limit (pg/mL) & 53.0 & & Upper limit (pg/mL) & 113.2 \\
\hline \multirow{3}{*}{$\begin{array}{l}\text { CLEIA-L1 (CRM-calibrated) } \\
\text { MS equivalent }\end{array}$} & Lower limit (pg/mL) & 46.1 & \multirow{3}{*}{$\begin{array}{l}\text { CLEIA-L1 (CRM-calibrated) } \\
\text { RIA equivalent* }\end{array}$} & Lower limit $(\mathrm{pg} / \mathrm{mL})$ & 96.4 \\
\hline & Median $(\mathrm{pg} / \mathrm{mL})$ & 50.0 & & Median $(\mathrm{pg} / \mathrm{mL})$ & 101.0 \\
\hline & Upper limit (pg/mL) & 53.9 & & Upper limit (pg/mL) & 105.6 \\
\hline \multirow{3}{*}{$\begin{array}{l}\text { CLEIA-L2 (CRM-calibrated) } \\
\text { MS equivalent }\end{array}$} & Lower limit (pg/mL) & 43.1 & \multirow{3}{*}{$\begin{array}{l}\text { CLEIA-L2 (CRM-calibrated) } \\
\text { RIA equivalent* }\end{array}$} & Lower limit (pg/mL) & 92.8 \\
\hline & Median (pg/mL) & 47.4 & & Median (pg/mL) & 98.0 \\
\hline & Upper limit (pg/mL) & 49.9 & & Upper limit (pg/mL) & 100.9 \\
\hline
\end{tabular}

* value converted from MS equivalent value to RIA equivalent value

We also did CRM calibration as reported previously ${ }^{4}$. 
Therefore, since the supply of the RIA kit was stopped in March 2021, it was decided to confirm the commutability between the measurement procedures. Furthermore, for plasma aldosterone concentration (PAC) 120 $\mathrm{pg} / \mathrm{mL}$ used for PA screening [9], it was decided to examine new correspondence values in nonRIA equivalent to RIA and standardized DCM and CLEIA.

In the results of the regression analysis with LCMS/MS (Fig. 2), the LC-MS/MS equivalent values for LC-MS/MS were approximated by correlation coefficients of $0.995-0.998$ for all measured values, the intercept was $-8.2 \mathrm{pg} / \mathrm{mL}$ to $-1.1 \mathrm{pg} / \mathrm{mL}$, and the slope was 1.045-1.065. This showed that the difference between the measurement methods was small. This is confirmed to be the result of the calibration curve being CRM calibrated and the high reaction specificity of the measurement procedure. This is due to the high specificity of measurement and small variation in measurement, including the performance of the antibody used in CLEIA.

On the contrary, the regression analysis of the RIA values for LC-MS/MS in all measurements showed correlation coefficients of $0.988-0.995$, intercepts of -10.5 to $61.0 \mathrm{pg} / \mathrm{mL}$, and slopes of $1.217-1.364 \mathrm{pg} / \mathrm{mL}$. This is due to the low specificity of the antibody used for RIA and the large variation in measurement.

However, the RIA equivalent value for LC-MS/MS included correlation coefficients of 0.995-0.998, intercept of 36.2-42.1 pg/mL, and slope of 1.237-1.536, and the difference between measurement procedures was small, although not shown in Fig. 2. This is because these CLEIA itself have high measurement specificity including antibody performance and small measurement variability. Furthermore, it is because it is a conversion value to the RIA value using the obtained LC-MS/MS equivalent value (Table 3 ).

In the results of the regression analysis with RIA (Fig. 3 ), the RIA values for RIA (Spac- $\mathrm{S}^{\circledR}$ ) included correlation coefficients of $0.984-0.989$ for all measured values, the intercept was $-83.9 \mathrm{pg} / \mathrm{mL}$ to $-34.5 \mathrm{pg} / \mathrm{mL}$, and the slope was $1.120-1.134$. The results were similar even with the measurement values that excluded the dilution measurement values. This showed that the difference between the measurement procedures was significant.

Furthermore, RIA equivalent value for RIA (Spac-S ${ }^{\circledR}$ ) showed that for all measurements, the correlation coefficient was $0.984-0.990$, the intercept was -46.5 to -22.1 $\mathrm{pg} / \mathrm{mL}$, and the slope was $1.009-1.278$. This showed that the difference between the measurement procedures was small. This is presumed to be due to the phenomenon as well as the behavior of the RIA value and the RIA equivalent value for LC-MS/MS. It is estimated that the large intercept of the regression equation is also affected by the characteristics of the calibration curve in RIA.

It is supposed that the results of the above correlation depend not only on the measurement performance of RIA and CLEIA, but also on the properties of the patient sample used in the correlation test. However, the correlation between the RIA value and the RIA equivalent value by the two kits of CLEIA was similar to the result described in the insert document for in vitro diagnostic medical device of the CLEIA kit $[10,11]$. This almost met the requirements of IVD Criteria Class II (Fig. 1). On the other hand, it was confirmed that in the CLEIA kits having reaction specificity, the consistency with the LC-MS/MS values was in agreement with the results described in the insert document for in vitro diagnostic medical device package of those kits $[12,13]$.

A summary of the comparison of the screening criterion between the measurement procedures is shown in Fig. 4. The RIA value of $120 \mathrm{pg} / \mathrm{mL}$ in the upper part of the figure is the current screening criterion [9]. This screening criterion is a comparison of the corresponding values of other measurement procedures, assuming that the performance of Spac-S ${ }^{\circledR}$ of RIA is maintained. The results calculated using the regression equation obtained from the correlation test showed that CLEIA-D1 and CLEIA-A1 were $52.2 \mathrm{pg} / \mathrm{mL}$ and $99.9 \mathrm{pg} / \mathrm{mL}$, respectively (Table 3 ). There was a double difference. As for these measurement procedures, the results of previous studies showed that they were $73.9 \mathrm{pg} / \mathrm{mL}$ and 140.1 $\mathrm{pg} / \mathrm{mL}$, respectively, and there was a double difference $(3,4)$. The ratio of these two was reproduced, but the corresponding value itself was different because the nonspecific reactivity of the measurement method by RIA itself depends on the characteristics of the patient sample used and the difference between lots of the kit. As a result, the RIA value itself is estimated to variation by about $20 \%$ as a relative value from the correlation analysis results.

The inside of the frame shown by the broken line in the middle of the figure is the corresponding value in the measurement method by CRM calibration. As a result, the corresponding values of LC-MS/MS, CLEIA-D2, CLEIA-A2, CLEIA-L1 and CLEIA-L2 were 48.5 $\mathrm{pg} / \mathrm{mL}, 43.4 \mathrm{pg} / \mathrm{mL}, 49.3 \mathrm{pg} / \mathrm{mL}, 50.0 \mathrm{pg} / \mathrm{mL}$, respectively. It was $47.4 \mathrm{pg} / \mathrm{mL}$. These LC-MSMS values and LC-MS/MS equivalent values were in good agreement (Table 3).

The lower part of the figure is the result of the middle part of the figure converted to the RIA equivalent value. As a result, the corresponding values of CLEIA-D2, CLEIA-A2, CLEIA-L1 and CLEIA-L2 were 106/9 $\mathrm{pg} / \mathrm{mL}, 106.9 \mathrm{pg} / \mathrm{mL}, 99.0 \mathrm{pg} / \mathrm{mL}$ and $93.9 \mathrm{pg} / \mathrm{mL}$, respectively. These LC-MS/MS equivalents were in good agreement (Table 3 ). These results reflect the 


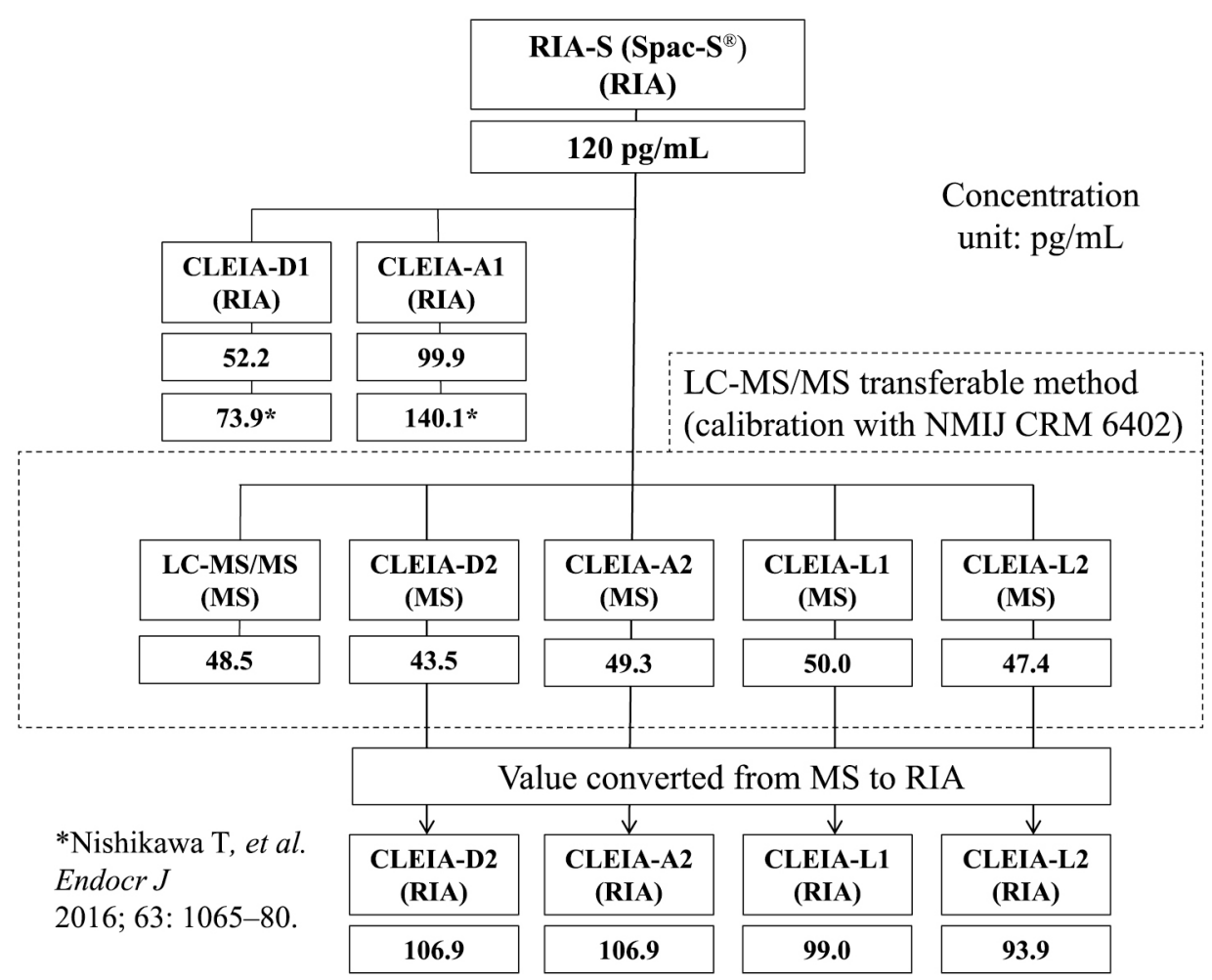

Fig. 4 Comparison of screening criterion between the measurement procedures.

(RIA): radioimmunoassay value and RIA equivalent value

(MS): mass spectrometry value and MS equivalent value
LC-MS/MS values and LC-MS/MS equivalent values in the middle of the figure. Of these, the results of CLEIAD1 and CLEIA-D2 are in agreement with the reported values because they are traceable to LC-MS/MS by calibration with CRM 6402 [14].

Based on these results, it became clear that CLEIA, a routine measurement procedure that replaces RIA, maintains commutability between kits by CRM calibration. It is assumed that the screening criterion in the measured values using these kits are new values as LC-MS/MS values and LC-MS/MS equivalent values, or a conversion formula may have been used.

The RIA value showed a significant difference between kits. The replacement CLEIA kit was shown to maintain commutability between kits by performing CRM calibration. It is suggested that the screening criterion in the measured values using these kits are new values as LC-MS/MS value and LC-MS/MS equivalent value, or a conversion formula may have been used for correspondence.

\section{Acknowledgments}

This study was partly supported by the Grand for Research on Intractable Diseases provided by the Japanese Ministry of Health, Labor and Welfare, and the Japanese Endocrine Society supported the present studies.

\section{Disclosure Statement}

The authors declare that they have no conflicts of interest, while Fujirebio Inc., Hitachi Chemical Diagnostic Systems Co. Ltd., Fujifilm Wako Pure Chemical Corp., and Aska Pharma supported the present studies.

\section{Author Contributions}

FS, YT, TY, HI, IK, HS, YO, MN and HS conducted the research, TN and KK edited the manuscript, TN and $\mathrm{KK}$ reviewed the manuscript. 


\section{References}

1. Review Committee on Standardization of Blood Aldosterone Measurements. Endocrine Society of Japan: Operational Guidelines for Standardization of Aldosterone Measurement in Daily Clinical Practice-Response to The Suspension of Supply of SPAC-S(RIA) Kit. (1st) April 2018, (2nd) February 2020 (In Japanese). http://www.jendo.jp/modules/news/index.php?content_id=55 accessed on Feb.18, 2020.

2. National Institute of Advanced Industrial Science and technology (AIST), National Metrology Institute of Japan Reference Material Certificate: NMIJ CRM 6402: Aldosterone in Human Serum. http://unit.aist.go.jp/qualmanmet/ refmate/crm/cert/6402b_J.pdf accessed on April 1, 2020.

3. Review Committee on Standardization of Blood Aldosterone Measurements: Standardization review committee for blood aldosterone measurement. Study report on standardization of aldosterone measurement in blood, February 29, 2016 (In Japanese).

4. Nishikawa T, Omura M, Kawaguchi M, Takatsu A, Satoh $\mathrm{F}$, et al. (2016) Calibration and evaluation of routine methods by serum certified reference material for aldosterone measurement in blood. Endocr J 63: 1065-1080.

5. Fries CM, Bae YJ, Rayes N, Sander B, Isermann B, et al. (2020) Prospective evaluation of aldosterone LC-MS/MSspecific cutoffs for the saline infusion test. Eur J Endocrinol 183: 191-201.

6. Taylor PJ, Cooper DP, Gordon RD, Stowasser M (2009) Measurement of aldosterone in human plasma by semiautomated HPLC-tandem mass spectrometry. Clin Chem 55: $1155-1162$.

7. Higashi T, Akaishi M, Yokota M, Suzuki T, Ogawa S, et al. (2018) A method for determination of aldosterone in adrenal tributary venous serum by derivatization using Girard $\mathrm{P}$ reagent isotopologues followed by LC/ESIMS/MS. J Chromatogr B Analyt Technol Biomed Life Sci 1092: 106-113.
8. Aldosterone Measurement Standardization Investigation Committee. Comparison and commutability confirmation test protocol (In Japanese). http://www.j-endo.jp/modules/ news/index.php?content_id=113 accessed on Sept 6, 2020.

9. Nishikawa T, Omura M, Satoh F, Shibata H, Takahashi K, et al. (2011) Guidelines for the diagnosis and treatment of primary aldosteronism-The Japan Endocrine Society 2009-. Endocr J 58: 711-721.

10. Hitachi Chemical Diagnostic Systems Co Ltd (2020) Insert document for in vitro diagnostic medical device. Determiner CL Aldosterone (3rd) Jun 2020 (In Japanese). http://www.pmda.go.jp/PmdaSearch/ivdDetail/ResultData SetPDF/230187_228AAEZX00039000_A_01_03 accessed on June 1, 2020.

11. Fujifilm Wako Pure Chemical Corp (2017) Insert document for in vitro diagnostic medical device. Accuraseed Aldosterone (6th) Jun 2017 (In Japanese). http://www. pmda.go.jp/PmdaSearch/ivdDetail/ResultDataSetPDF/ 890027_227AAAMX00030000_A_01_02 accessed on Nov. 1, 2017.

12. Fujirebio Inc (2020) Insert document for in vitro diagnostic medical device. Lumipulse Presto Aldosterone (2nd) Nov 2020 (In Japanese). http://www.pmda.go.jp/Pmda Search/ivdDetail/ResultDataSetPDF/670773_301AAEZX 00037000_A_01_03 accessed on Nov. 1, 2020.

13. Fujirebio Inc (2020) Insert document for in vitro diagnostic medical device. Lumipulse G Aldosterone (3rd) Nov 2020 (In Japanese). http://www.pmda.go.jp/PmdaSearch/ ivdDetail/ResultDataSetPDF/670773_301AAEZX000 36000_A_01_03 accessed on Nov. 1, 2020.

14. Teruyama K, Naruse M, Tsuiki M, Kobayashi H (2021) Novel chemiluminescent immunoassay to measure plasma aldosterone ad plasma active renin concentrations for the diagnosis of primary aldosteronism. J Hum Hypertens doi: 10.1038/s41371-020-00465-5. Online ahead of print. 